\title{
Psychological approaches to the treatment of chronic pain
}

\author{
H. MERSKEY \\ D.M., F.R.C.P., F.R.C.P.(C), F.R.C.Psych. \\ University of Western Ontario and London Psychiatric Hospital
}

\section{Introduction}

Much of the earlier writing on the psychology of pain fails to distinguish between acute pain and chronic pain. Some authors studied chronic pain, explicitly defining their population by the duration of the complaint. The differences between acute and chronic pain were particularly emphasized by Sternbach $(1968,1974)$. Watson (1983) delineates chronic pain very effectively as follows: '... persisting past one month or past the usual time for the particular disorder to heal. It usually lacks evidence of autonomic hyperactivity'.

A number of the psychological observations which apply to acute pain also apply to chronic pain. But not all of them matter as much. For example, anxiety and anticipation often make acute pain worse. This is particularly notable before operation. They are not nearly so prominent in respect of chronic pain. Similarly a sense of control of the situation often eases acute anxiety or pain. This can be inferred from the animal literature, e.g. Mowrer and Viek (1948) and has sometimes been shown in adults (Bowers, 1968; Thompson, 1981), and in children (McGrath, 1983).

It has been generally considered since the work of Beecher (1955) that a placebo effect can be found in $35 \%$ of patients with postoperative pain and other acute conditions. This is rarely the experience of anyone treating chronic pain. In the case of chronic pain, patients are often no longer anxious but are more often depressed. Many of them have learnt, or have taught themselves, subjective techniques of pain control. Frequently, these involve distractions or an alternative method of occupation. Sometimes they find a way to occupy themselves with a task in the presence of distracting stimuli which are deliberately provided; usually this is the radio. It is interesting that Morgenstern (1964) demonstrated that a combination of tasks and distracting stimuli, like flashing

Correspondence: H. Merskey, D.M., Director of Education and Research, London Psychiatric Hospital, 850 Highbury Avenue, P.O. Box 2532, Terminal 'A', London, Ontario, Canada N6A 4HI. lights and variable repeated noises helped to reduce pain. However, if patients do reach the doctor for. treatment it can be assumed that even though thei efforts in this direction may have had some success, they have not been enough to produce the relies which is needed.

\section{Basic concepts of pain}

In the evaluation of patients with pain it i⿱日 important to define basic concepts. Most people interested in the field favour the view that pain has to be regarded as a subjective phenomenon, whatever its cause. The pain from which psychiatric patient suffer is usually not distinguishable subjectively from pain which has other causes, although in a few cases the characteristics of the descriptions of pain or the associated features may help to achieve distintinco tions between pain which is due to psychologicas factors and pain which is due to lesions. Thus, mosi psychiatric patients with pain describe their pain in terms similar to the terms of organic disease but in $\vec{\Phi}$ few instances discriminating techniques will separate some members of the groups (Leavitt and Garron 1979).

For some years I have felt it best not to use the description 'psychogenic pain'. This is for two rea sons. First the original notion of a psychogeniog symptom of any sort was one in which a physicat disorder caused the psychological state (Lewiş, 1972) The term has suffered a reversal of usage since if now, sometimes, but not always, means a symptom? with psychological causes. Second, if 'psychogenie pain' is accepted as an entity this gives credence t the idea that it is not really the same to the patient as true or so-called 'genuine' pain-which of course has to be organic (who ever heard doctors, even psychia trists or psychologists, talk of 'genuine' learned behaviour?). Accordingly, it seems best not to regar 'psychogenic' pain as totally distinct from 'organice pain. This is not to say that we may not recognizक some differences. We must recognize patterns in causation whether organic or psychiatric or both 
Thus it is advisable to see pain as a fundamentally unitary phenomenon, albeit with various causes.

Those who have a philosophical interest may agree that this amounts to a monistic attitude to the properties of the condition and a dualistic, Descartian attitude to its causes. The approach recommended requires one to talk of pain of psychological origin or pain of organic origin or pain which has both causes. That is a little cumbersome but retains the unitary attitude to pain without giving up the clinical need for discrimination.

\section{Psychiatric considerations}

A few cases of acute anxiety or hysteria present with pain. Cardiac neuroses such as effort syndrome, or precordial pain mimicking angina or resembling coronary disease, can be due to sudden stress or emotional conflict. The majority of pain problems in psychiatric practice represent pain of at least several months duration and this is what is discussed in this section.

If psychiatric considerations are important in patients with chronic pain, it becomes relevant to know what diagnoses should be considered. Four can be mentioned. First, it is very rare to find pain due to schizophrenia as a consequence of significant delusions or hallucinations. However a significant minority of schizophrenic patients have headache or other somatic complaints. The somatic complaints often have a minor organic basis, e.g., from trauma. The headache seems to be associated with the illness but has not been well analysed as to whether it is related to thought processes or muscle tension, or susceptible to any other explanation. In any case, these complaints are not often the source or a focus of major concern to the patient. Second there is a wellrecognized group of patients who are in the minority in all, or almost all, published studies and who have a classical endogenous depression. These cases may have pain on a delusional basis (e.g., jabbing pains from punishment being inflicted on them) or, much more often, because associated anxiety produces muscle tension. The majority of patients with endogenous depression however do not have notable pain symptoms. Everyone loves to comment on the few patients with pain and classical endogenous depression and even more to diagnose them because they represent one relatively small group where treatment is often very effective and the results are very gratifying. Moreover, they are interesting conceptually.

Third, there is a somewhat larger group of patients who have reactive depressions and in whom pain, especially headache, is a common symptom. These patients, too, respond quite well to the usual treatments for depression. They often show some neurotic mechanisms such as anxiety to which the pain can be attributed. Fourth, there are patients who have essentially neurotic conditions such as anxiety, often with hysterical symptoms or personality abnormalities. These form the bulk of psychiatric patients who are seen in pain clinics or who have chronic pain which is a major problem. There are a number of ways of categorizing them besides the traditional ones which I have used. The term 'learned pain' or 'operant pain' is one such set of terms which partly overlaps with these notions. The classification system of the American Psychiatric Association in the third Diagnostic and Statistical Manual (DSM-III) covers some of these patients with the term 'somatization disorder' which is a version of what others have called 'Briquet's syndrome' (Guze, 1970) and delineates a number of these patients but not all of them. Conversion disorders and histrionic personality refer to others, but not exclusively to patients with pain. There is also an understandable overlap between endogenous and reactive depresions and a further overlap between reactive depression and the neurotic disorders.

Insofar as a distinct psychiatric diagnosis can be made, the guidelines for treatment are clear. Schizophrenic patients normally require phenothiazines as well as some quite specific social management and attention to the parts played by their families. Those with endogenous depression respond well to antidepressants and those with reactive depression also gain benefit from medication. In both categories, and especially in those with reactive depression, psychological support or exploratory psychotherapy is useful and environmental manipulation is often required. Anxiety states respond somewhat to antidepressants and also to both exploratory psychotherapy and behavioural techniques such as relaxation and deconditioning. Benzodiazepines should be avoided since they do not provide satisfactory long-term medication and this population is at obvious risk of drug dependence.

Where the predominant phenomena are hysterical or related to intractable personality syndromes the prognosis is less good. Management in these cases may be quite effective on a general practitioner level and may not be much better on the part of those who have much greater specialization in this field.

However, perceptive handling of these patients can make a worthwhile difference. The doctor's preference, and mastery of particular techniques, will usually determine which measures he employs in those situations. They are a very specialized psychiatric problem and need not detain us here. Overall, the general methods of psychiatric management of patients who focus on their body are very important in the care of many chronic pain patients. This applies also to patients with cancer pain. 


\section{Secondary emotional changes}

There is evidence (Woodforde and Merskey, 1972; Sternbach, 1974) that patients with significant lesions develop secondary emotional changes. This is hardly surprising. Some of these changes include irritability, frustration, subjective depression, and reduction of sexual interest (Pelz and Merskey, 1982). There is, of course, impairment of sporting and recreational activities as well as work and a corresponding degree of dissatisfaction in many instances. The depression in about $10 \%$ of patients in pain clinics may reach the level of significant illness (Pilowsky, Chapman and Bonica., 1977) but is much more often a pattern of symptoms as just indicated. Many of these secondary changes will respond to treatment of the primary condition or to organic procedures which produce pain relief. The latter include physiotherapy, exercise, transcutaneous electrical nerve stimulation (TENS), minor analgesics, and surgery. Psychotropic medication, especially phenothiazines and amitriptyline has some organic basis for its effects even when psychiatric illness is not to be found (Monks and Merskey, 1984).

\section{The main problem}

The commonest problem in pain clinics and perhaps in the practice of most doctors is the patient who has a lesion and also some evidence of emotional disturbance. The emotional disturbance may be independent and make the pain worse whether the lesion is a major one or a minor one, and it may at times be the main factor in producing the pain. The commonest situation in pain clinics is that personality disorders promote the complaint of pain and the emphasis upon it. Difficulties within the family, the possibility of compensation, complications from the use of drugs and dependence on them all compound these problems. Frequently, there has been excessive somatic treatment and sometimes excessive psychiatric treatment. Many of these issues are dealt with in the chapter on 'Behavioural Science and Chronic Pain' (Fordyce, 1984, this issue).

In general, the first step is to convince the patient that the doctor truly believes that he has pain. Nothing works better in this context than a comprehensive evaluation of the patient's condition. It is essential for every practitioner who becomes involved with a patient with chronic pain to establish for the patient that he has taken the main complaint seriously. This means reviewing and if necessary recording in detail the features of the pain, the extent to which it disturbs the patient's life, the things that have been done for it, and the measures that might or might not relieve him. If such an approach is adopted it then becomes very acceptable to the patient to have enquiries made into his psychological status, whether the pain has affected him, what emotional conditions may make the pain worse, and so forth. This pragmatic and sympathetic approach frequently enables the patient to express and discharge much feeling about the troubles which his pain has given him. It is essentially supportive but occasionally will serve to explore emotional difficulties.

Once the main lines of this approach have been established the next requirement is to work on any and every measure which is relatively harmless and which may produce some improvement. These measures may be physical but are important psychologically. It is obvious that physical measures of treatment like physiotherapy, exercise, nerve blocks, TENS, medication, all serve to encourage the patient in the belief that he may get better. There can be times when some of them serve in a disadvantageous fashion to help him believe that the responsibility for getting better is not in his hands. But there is no reason in principle why a variety of physical measures should not be employed, and have some placebo benefits, without committing either the patient or the doctor to the view that psychological issues must be neglected. In such a context of care and attention and support it may be more possible to look at different issues in the patient's life which need to be reviewed than in any other context. These issues include the obvious considerations as to whethef family relationships are satisfactory, whether the patient has a difficult boss (if he or she is stiff employed), and whether he or she is engaging in enough activity or other steps to relieve the pain by distraction or concentration or any other psychological process. Against this background of general support and care, arrangements can then be made to review or introduce a number of other more specialized approaches.

\section{More specialized methods}

Table 1 shows a number of the approaches which have been adopted with some sample references on their description or evaluation. Those interested in more detail of particular approaches can refer to the sources cited. Interestingly, I have not found any extensive discussion of supportive psychotherapy and pain, although it is the form which is perhaps most often recommended. The following represents general comments upon the various approaches.

Analytic psychotherapy was originally fostered by authors like Hart (1947) and Engel (1951, 1959). On the whole, its success in the treatment of psychiatric patients with pain has been limited and it is little used in chronic pain patients in pain clinics. Modifications of analytic psychotherapy offer some promise for a sub-group. Brief dynamic psychotherapy which is developed from the foregoing is the most attractive 
TABLE 1. Specialized techniques available for psychological management in chronic pain

\begin{tabular}{|c|c|}
\hline Analytic psychotherapy & Pilowsky, 1978 \\
\hline Psychodynamic treatment & Pilowsky and Bassett, 1982 \\
\hline $\begin{array}{l}\text { Supportive psycnotherapy } \\
\text { Family therapy }\end{array}$ & $\begin{array}{l}\text { Roy, 1982; Waring, 1982; } \\
\text { Fordyce, } 1976\end{array}$ \\
\hline Group therapy & $\begin{array}{l}\text { Pinsky et al., 1979; Baptiste } \\
\text { and Herman, } 1982\end{array}$ \\
\hline Milieu therapy & Herman and Baptiste, 1981 \\
\hline Cognitive therapy & $\begin{array}{l}\text { Tan, 1982; Turner and } \\
\text { Chapman, 1982;Turk } \\
\text { et al., } 1984\end{array}$ \\
\hline Operant therapy & $\begin{array}{l}\text { Fordyce, 1976; Turner and } \\
\text { Chapman, } 1982\end{array}$ \\
\hline Hypnosis & Barber and Adrian, 1983 \\
\hline Combined techniques & Roy and Tunks, 1982 \\
\hline
\end{tabular}

form of treatment to be considered. Malan (1976) and his colleagues have shown that brief dynamic therapy (say up to 9 sessions) can define particular problems in patients' lives and resolve them with the participation of the patient. There is no reason to think that pain may not similarly resolve in some instances when it represents a major psychological problem in an individual's life. However, these instances will be limited to a small group.

Supportive psychotherapy is advocated strongly by Pilowsky and Bassett (1982) who write '(it) ... aims to support and strengthen the patient's own coping mechanisms ... with no attempts ... to challenge defences. The therapist is usually more active and positive with maximal reality testing and encouragement ... in the management of pain patients supportive psychotherapy is often the patient's major therapy'. I concur fully with this although published formal evidence for it is lacking. In one unpublished study (Hall, 1980) it was shown that supportive psychotherapy was valuable. Group psychotherapy is of use, probably, in patients who have already entered into programmes within specialized clinics. There are few, if any, reports of group psychotherapy or patients who have that modality of treatment alone. The results described by Pinsky et al. (1979) and Catchlove and Cohen (1982) show however that group approaches based on a dynamic model and combined with other types of treatment can produce excellent results comparable with those from other types of programme.

Cognitive therapy is logical and has been shown by Khatami and Rush (1982) to work for specific individuals in pain at specific points in their care. Its overall value remains subject to assessment. Extensive reviews of this have been provided by Tan (1982) and also by Turner and Chapman (1982). Detailed methods of treatment can be found in the book by Turk, Meichenbaum and Genest (1983). Miller and Berman (1983) review cognitive therapy in general.
Perhaps the essential feature of cognitive therapy is to make systematic what we all think of doing empirically, such as distancing oneself from pain and saying 'It isn't really me that is suffering', or favouring distraction techniques which emphasize something different like pleasant experiences (thinking about some nice experience which may help to reduce the impact of current pain) and so forth.

The methods which are classed as cognitive therapy are very varied. Tan (1982) mentions the provision of preparatory information, prepared childbirth techniques and 'coping skills'. The latter comprise strategies like imaginative inattention ('think of a pleasant day at the beach'), imaginative transformation of the pain ('those sensations are really contractions, not pain'), imaginative transformation of the context ('that hurts but it's like being the hero in a James Bond film'), diversion of attention (counting ceiling tiles, doing mental arithmetic) and somatization (focusing on the part in pain but analysing the experience as if for a biology report). Relaxation, deep breathing exercises, the provision of external distractions (e.g., tasks which pre-occupy the individual or variable noises) all form part of the complex of strategies which may be called cognitive therapy. Some workers, especially Turk $e t$ al. (1984), have developed 'stress innoculation procedures' in which the individual is exposed to painful or noxious stimuli, usually in the laboratory, as part of a process of becoming accustomed to the painful situation and adapting to it with the various cognitive techniques recommended.

On the whole, it seems that cognitive therapy may have some benefit but this is still speculative. There is reason to think that it may work best in pain of mild or moderate severity (cf. Melzack, Weisz and Sprague, 1963)). It tends not to prove popular with patients when the pain is severe. It then produces, apparently, only very limited gains. However, since all the gains with cognitive therapy are got at the expense of little or no risk to the patient, they deserve always to be considered and sometimes at least to be sought out.

Hypnosis is sometimes linked with cognitive therapy. In the writer's view hypnosis is just one form of suggestion and has nothing to commend it over other modes of suggestion except that it too is usually harmless. Occasionally, patients and their therapists get into a mess with it but that is not common. The reader who wants a sceptical view of hypnosis can refer to Merskey (1971). A discussion of its place in treatment today by those who use it is available in the volume by Barber and Adrian (1983).

Like hypnosis, behavioural methods are often linked in discussion with cognitive ones. They have preceded cognitive techniques in development. Their formal development is principally due to Fordyce 
(Fordyce et al., 1968; Fordyce, 1976) and since his first description they have become increasingly popular, particularly in North America. The kernel of this approach is provided by the notion that conditioning will reduce or abolish 'pain behaviour'. In operant conditioning, as distant from classical conditioning, behaviour is increased if it is rewarded ('reinforced') and decreased if not rewarded ('negative reinforcement') or otherwise discouraged. Chronic pain patients are held to show much pain behaviour which distorts their lives and which they may use as a form of interpersonal manipulation. Following from this it is argued that pain is 'learnt' or 'unlearnt' and that a successful operant programme would enable patients to unlearn the pain which has been manifest in their pain behaviour. There are conceptual problems in this viewpoint to be discussed shortly.

It has long been recognized that active rehabilitative measures and concentration upon positive endeavours is beneficial to patients with both psychological and physical disorders. Exercise has also been seen to be valuable - despite initial pain from it-in many musculoskeletal disorders. Travell et al. (1942) observed that disuse gave rise to muscle pain. It is therefore appropriate to expect that any approach which includes these features will have advantages for at least some chronic pain patients. The specific operant procedure requires that patients be reinforced positively by the responses of staff if they are active and uncomplaining, and that they receive the reverse treatment if they do little or talk about their pain.

Some good results have undoubtedly followed from operant programmes (Greenhoot and Sternbach, 1974; Newman et al., 1978; Roberts and Reinhardt, 1980). In a fairly representative report, Cairns et al. (1976) describe the results when behavioural approaches were employed in the second phase of treatment of a severely disabled group of low back pain patients, the first phase covering regional blocks and other somatic techniques. A postal survey of 100 patients, averaging ten months from discharge, elicited replies from 90 of whom $70 \%$ were improved and $75 \%$ were working. Typically, in this report as in others, it is hard to disentangle the pure effects of the operant approach from other things which are going on at the same time. Increased activity and a reduction in medications used for pain, however, are common results of behavioural programmes. The latter effect is often obtained by offering the patient a 'pain cocktail' through which the medication taken is reduced without the patient being able to see the size of a decrease or when it is made. These particular types of change seem to be reported more often from behaviourally orientated centres.

Fordyce (1982) has no difficulty in making a sound case that the behaviour of patients in pain is influenced by environmental factors. Sternback (1983) has noted, however, that there is no proof tha operant programmes work any more than otherinterventions because operant programmes hav never been studied in an adequate controlled fashion In practice it is extremely difficult to isolate operan measures and present them as part of a totaf programme controlled by another programme i which the sole difference is the absence of specificallo operant activity by the therapists. Linton (1982) has assessed the situation in the treatment of chronic pai $\vec{B}$ other than headache not only in regard to studies of operant conditioning but also with respect to relaxat tion in cognitive and multimodal behavioural apo proaches. He says in general the quality of the studies was poor...few data were found whict conclusively demonstrate that any of the approaches are effective or they are the treatment of choice'. Hed adds, however, that the data do imply that behav ioural approaches may help patients lead more normal and productive lives and agrees that the literature suggests that '(1) the operant methods lead' to increased activity levels and decreased pain and drug intake; (2) the relaxation approach results io decreased electromyogram levels and some paip reduction; (3) the cognitive techniques are speculas tive at this time; and (4) the multimodal metbo regularly produces a variety of improvements butiơ $\bar{E}$ diversity of the treatments makes general statemente about utility impossible'.

The neglect of the experience of the patient is ond aspect of the behavioural approach which remains unacceptable to the present writer. There need be n $\overline{8}$ objection to recognizing that it is unhelpful fof patients and their relatives to persist in ruminating about and talking about pain and avoiding an constructive activities. But it is also difficult te suppose that when pain is promoted by movement will be abolished as a result of operant relearning? rather than because, after substantial exercise, the muscular status and respondent input of the indivi dual will be changed. Likewise, even if unwante behaviour is diminished, it seems very unlikely that the experience of pain will go away unless some othe? change has been effected, either in the individual's physical status or in his thought processes. Tho patient is likely to comment that he still has his paip but he is not permitted to mention it. Special efforts. are needed to get around this particular conflict of attitude between patient and practitioner. In any case, such methods would not resolve the conceptuat dilemma. Any approach which insists on speaking only of 'pain behaviours' whilst skirting around the nature of the subjective experience, is likely to leave $\$$ significant group of doctors and patients dissatisfied with its comprehensive quality. The usual answer tơ this is that the patient's descriptions of his experience 
are part of his behaviour and that is how we know about it and it will be taken into consideration. Nevertheless, in practice the behaviourist approach seems to make a virtue of discounting the subjective experience and is accordingly deficient.

\section{Conclusions}

The theme of this article has been to emphasize that there is an important field for psychiatric and psychological contributions in the management of chronic pain. Some of the limitations of these approaches have also been expressed. I believe that the best approach is founded upon a clear concept of pain. I have criticized attempts to discount the subjective experience. At the same time behavioural methods have a role to play in comprehensive management. As is so often the banal case, an eclectic and comprehensive position should appeal to all those who agree that no single current theory is adequate on its own. This can also be expected to be more practical and to offer the best chance of effective treatments.

\section{References}

BAPTISTE, D. \& Herman, E. (1982) Group therapy: a specific model. In: Chronic Pain: Psychosocial Factors in Rehabilitation. (Eds. R. Roy and E. Tunks), p. 166. Williams \& Wilkins, Baltimore/London.

Barber, J. \& Adrian, C. (1983) Psychological Approaches to the Management of Pain. Brunner/Mazel, New York.

BEECHER, H.K. (1955) The powerful placebo. Journal of the American Medical Association, 159, 1602.

BOWERS, K.S. (1968) Pain, anxiety, and perceived control. Journal of Consulting and Clinical Psychology, 32, 596.

Cairns, D., Thomas, L., Mooney, V. \& Pace, B. (1976) A comprehensive treatment approach to chronic low back pain. Pain, 2, 301.

Catchlove, R. \& Cohen, K. (1982) Effects of a directive return to work approach in the treatment of Workman's Compensation patients with chronic pain. Pain, 14, 181.

ENGEL, G.L. (1951) Primary atypical facial neuralgia: An hysterical conversion symptom. Psychosomatic Medicine, 13, 375.

ENGEL, G.L. (1959) 'Psychogenic' pain and the pain-prone patient. American Journal of Medicine, 26, 899.

FORDYCE, W.E. (1976) Behavioral Methods for Chronic Pain and Illness. C. V. Mosby, St. Louis.

FORDYCE, W.E. (1982) A behavioural perspective on chronic pain. British Journal of Clinical Psychology, 21, 75.

FORDYCE, W.E. (1984) Behavioural science and chronic pain. Postgraduate Medical Journal, 60, 865.

FoRDYCE, W.E., FOWLER, R., LEHMANN, J. \& DeLATEUR, B. (1968) Some implications of learning in problems of chronic pain. Journal of Chronic Diseases, 21, 179.

GREenHOOT, J.H. \& STERNBACH, R.A. (1974) Conjoint treatment of chronic pain. In: Advances in Neurology: Pain, Vol. 4. (Eds. J. J. Bonica), p. 595. Raven Press, New York.

GUZE, S.B. (1970) The role of follow-up studies: Their contribution to diagnostic classification as applied to hysteria. Seminars in Psychiatry, 2, 392.

HALL, R.C.W. (1980) A comparison of tricyclic antidepressants and analgesics in the management of chronic post-operative surgical pain (unpublished data).

HART, H. (1947) Displacement, guilt and pain. Psychoanalysts Review, 34, 259.
Herman, E. \& BAPTiste, S. (1981) Pain control: Mastery through group experience. Pain, 10, 79.

Khatami, M. \& Rush, A.J. (1982) A one year follow-up of the multimodal treatment for chronic pain. Pain, 14, 45.

LEAVITT, F. \& GARRON, D.C. (1973) The detection of psychological disturbance in patients with low back pain. Journal of Psychosomatic Research, 23, 149.

LEWIS, A. (1972) 'Psychogenic': A word and its mutations. Psychological Medicine, 2, 209.

LiNTON, S.J. (1982) A critical review of behavioural treatments for chronic benign pain other than headache. British Journal of Clinical Psychology, 21, 321.

MCGRATH, P.A. (1983) Modulation of acute pain and anxiety for paediatric oncology patients. American Pain Society Abstracts, 106.

Malan, D. (1976) The Frontier of Brief Psychotherapy. Plenum Press, New York.

MelzaCK, R., Weisz, A.Z. \& SpRague, L.T. (1963) Stratagems for controlling pain: Contributions of auditory stimulation and suggestion. Experimental Neurology, 8, 239.

Merskey, H. (1971) An appraisal of hypnosis. Postgraduate Medical Journal, 47, 572.

Miller, R.C. \& Berman, J.S. (1983) The efficacy of cognitive behavior therapies: A quantitative review of the research evidence. Psychology Bulletin, 94, 39.

MONKS, R. \& MERSKEY, H. (1984) Treatment with psychotropic drugs. In: Textbook of Pain. (Eds. P. D. Wall and R. Melzack). Churchill Livingstone, London.

MORGENSTERN, F.S. (1964) The effects of sensory input and concentration on post-amputation phantom limb pain. Journal of Neurology, Neurosurgery and Psychiatry, 27, 58.

MOWRER, O.H. \& VIEK, P. (1948) An experimental analogue of fear from a sense of helplessness. Journal of Abnormal and Social Psychology, 43, 193.

Newman, R.I., Seres, J.L., YosPe, L.P. \& Garlington, B. (1978) Multi-disciplinary treatment of chronic pain: Long-term followup of low back pain patients. Pain, 4, 283.

Pelz, M. \& Merskey, H. (1982) A description of the psychological effects of chronic painful lesions. Pain, 14, 293.

PILOWSKY, I. (1978) Psychodynamic aspects of the pain experience. In: The Psychology of Pain. (Ed. R. A. Sternbach), p. 203. Raven Press, New York.

PILOWSKY, I. \& BASSETT, D. (1982) Individual dynamic psychotherapy for chronic pain. In: Chronic Pain: Psychosocial Factors in Rehabilitation. (Eds. R. Roy and E. Tunks), p. 107. Williams \& Wilkins, Baltimore/London.

Pilowsky, I., Chapman, C.R. \& Bonica, J.J. (1977) Pain, depression and illness behavior in a pain clinic population. Pain, 4, 183.

Pinsky, J.J., Griffin, S.E., AGNew, D.C., Kamdar, M.D., Crue, B.L. \& PINSKY, L.H. (1974) Aspects of long-term evaluation of pain unit treatment progam for patients with chronic intractable benign pain syndrome: Treatment outcome. Bulletin of the Los Angeles Neurological Society, 44, 53.

ROBERTS, A.H. \& REINHARDT, L. (1980) The behavioral management of chronic pain: Long-term follow-up with comparison groups. Pain, 8, 151.

RoY, R. (1982) Marital and family issues in patients with chronic pain. A review. Psychotherapy and Psychosomatics, 37, 1.

RoY, R. \& TUNKS, E. (1982) Chronic Pain: Psychosocial Factors in Rehabilitation. Williams \& Wilkins, Baltimore/London.

SternbaCh, R.A. (1968) Pain: A Psychological Analysis. Academic Press, New York.

STERnBACH, R.A. (1974) Pain Patients. Traits and Treatment. Academic Press, New York.

STERNBACH, R.A. (1983) Fundamentals of psychological methods in chronic pain. In: Advances in Pain Research and Therapy, Vol. 5. (Eds. J. J. Bonica, U. Lindblom and A. Iggo), p. 777. Raven Press, New York.

TAN, S.-Y. (1982) Cognitive and cognitive behavioural methods for pain control: A selective review. Pain, 12, 201.

ThOMPSON, S.C. (1981) Will it hurt less if I can control it? A 
complex answer to a simple question. Psychological Bulletin, 90 , 89.

Travell, J., Rinzler, S. \& Herman, M. (1942) Pain and disability of the shoulder and arm: Treatment by intramuscular infiltration with procaine hydrochloride. Journal of the American Medical Association, 120, 417.

Turk, D.C., Meichenbaum, D. \& Genest, M. (1984) Pain and Behavioral Medicine. Guildford Press, New York.

TURNER, J.A. \& ChAPMAN, C.R. (1982) Psychological interventions for chronic pain: A critical review. II. Operant conditioning, hypnosis and cognitive-behavioral therapy. Pain, 12, 23.
WARING, E.M. (1982) Conjoint marital and family therapy. In: Chronic Pain: Psychosocial Factors in Rehabilitation. (Eds. R. Roy and E. Tunks), p. 151. Williams \& Wilkins, Baltimore/ London.

WATSON, C.P.N. (1983) Chronic pain. Modern Medicine of Canada, 38, $11,1365$.

WoOdforde, J.M. \& MerskeY, H. (1972) Personality traits of patients with chronic pain. Journal of Psychosomatic Research, 16, 167. 